\title{
Rancang Bangun Aplikasi E-Learning di LBB Primagama Malang dengan Implementasi Konsep Gamifikasi
}

\author{
Muhammad Shulhan Khairy, Dimas Wahyu Wibowo, Muhammad Dio Syahrizal
}

\begin{abstract}
Recently, e-learning as a learning media has been developed rapidly. But students have lack of interest to learn because of their ability of self-study. We develop e-learning system with gamification concepts to solve that problem. Gamification concepts that implemented to the system includes point, badge, reward, and leaderboard. We also implement gamification element such as game mechanic, game design, and game thinking. The system tested to the students and got improvement $81,60 \%$ for interest to learn.
\end{abstract}

Index Terms-e-learning; game; gamification; learning media.

Abstrak-- Pesatnya perkembangan dunia teknologi informasi membuat penggunaan e-learning sebagai media pembelajaran semakin meningkat. Namun terdapat kekurangan yaitu kurangnya minat belajar peserta didik karena ketidakmampuan peserta didik untuk belajar mandiri. Untuk mengatasi masalah tersebut maka dikembangkan sistem e-learning dengan menerapkan konsep gamifikasi. Konsep gamifikasi yang diterapkan meliputi 4 elemen, yaitu poin, badge, reward, dan leaderboard, serta unsur gamifikasi yang meliputi game mechanic, game design, dan game thinking. Hasil implementasi diujikan dengan mengukur peningkatan minat belajar para siswa dengan hasil rata-rata nilai sebesar $81,60 \%$.

Kata Kunci-e-learning; game; gamifikasi; media belajar.

\section{Pendahuluan}

Ceiring dengan perkembangan teknologi informasi Nyang semakin pesat, kebutuhan akan sebuah mekanisme belajar mengajar berbasis teknologi informasi menjadi tidak terelakkan lagi. Gabungan antara dunia teknologi informasi dengan proses belajar

Muhammad Shulhan Khairy berafiliasi pada Jurusan Teknologi Informasi Politeknik Negeri Malang, Indonesia. (e-mail: khairy@polinema.ac.id).

Dimas Wahyu Wibowo berafiliasi pada Jurusan Teknologi Informasi Politeknik Negeri Malang, Indonesia. (e-mail: dimasw@polinema.ac.id).

Muhammad Dio Syahrizal berafiliasi pada Jurusan Teknologi Informasi Politeknik Negeri Malang, Indonesia. (e-mail: diosyahrizal@gmail.com). mengajar dikenal dengan sebutan e-learning atau dalam Bahasa Indonesia disebut sistem pembelajaran daring. E-Learning merupakan aplikasi yang memanfaatkan teknologi internet dan berfungsi menghubungkan antara pendidik dan peserta didik dalam sebuah ruang belajar daring. Hal ini tercipta untuk mengatasi keterbatasan antar pihak pendidik dan peserta didik dalam hal waktu dan ruang. Dengan e-learning, maka proses pendidikan dapat berjalan kapan saja dengan mengabaikan kedua hal tersebut. Maka dari itu e-learning membawa pengaruh terjadinya transisi pendidikan konvensional menjadi dalam bentuk digital (Kusmana, 2011).

Permasalahan yang ada dalam penggunaan elearning sebagai media pembelajaran antara lain ketidakmampuan peserta didik dalam belajar mandiri serta rendahnya motivasi belajar yang berakibat pada tidak tercapainya tujuan pembelajaran (Sari). Padahal, motivasi dalam belajar akan berdampak pada capaian pembelajaran (Rozi, Rosmansyah, \& Dabarsyah, 2019). Salah satu cara untuk mengatasi masalah tersebut adalah dengan diterapkannya konsep gamifikasi pada platform e-learning. Secara konsep, gamifikasi dapat diterapkan pada platform e-learning (Handani, Suyanto, \& Sofyan, 2016). Penerapan konsep gamifikasi dapat memberikan dampak peningkatan motivasi belajar, atensi, dan performa belajar (Barrio, Organero, \& Soriano, 2016).

Penerapan konsep gamifikasi telah dilakukan pada berbagai macam ranah seperti pada pembelajaran huruf kanji (Fathoni \& Delima, 2016), pembuatan aplikasi berbasis VR (virtual reality) (Heryadi, Robbany, \& Sudarma, 2016), pembelajaran kimia dengan pendekatan board game (Wu, Chen, Wang, \& Hou, 2018), pengembangan aplikasi mobile (Tóth \& Tóvölgyi, 2016), permainan untuk orang tua (Rienzo \& Cubillos, 2019), sebagai solusi untuk meningkatkan kemampuan interaksi anak autis (Mubin \& Poh, 2019), sebagai pendukung pariwisata (Prakasa \& Emanuel, 2019).

Minat siswa-siswi pada sekolah menengah secara umum di Kota Malang, Jawa Timur sangat tinggi untuk mengikuti pembelajaran tambahan yang didapatkan di lembaga bimbingan belajar (LBB). Tentunya LBB diharapkan memberikan dampak yang lebih baik pada peningkatan penguasaan pelajaran, tak terkecuali pada LBB Primagama Malang. Sebagai salah satu LBB yang 
ternama, penerapan konsep gamifikasi pada platform pembelajaran daring atau e-learning dapat mejadi alternatif agar minat belajar dari peserta didik meningkat dan memberikan hasil yang positif terhadap kemampuan yang dimiliki oleh para siswa.

\section{METODE PENELITIAN}

\section{A. Metodologi Pengembangan Sistem}

Proses pengembangan perangkat lunak dilakukan dengan menggunakan salah satu framework dari metodologi Agile yaitu Kanban. Kanban adalah suatu metode pengembangan perangkat lunak untuk menvisualisasikan proses perkerjaan yang dilakukan saat sedang mengembangkan sebuah perangkat lunak.

Metode Kanban tidak memerlukan detil dari sebuah peran dalam tim pengembangan perangkat lunak seperti proses sprint pada Scrum. Visualisasi pada Kanban digunakan untuk merepresentasikan setiap langkah dan proses secara jelas sehingga setiap anggota tim pengembangan dapat memahami kondisi yang ada. Hal tersebut direpresentasikan pada Kanban board. Pada board tersebut dapat dilakukan prioritisasi pekerjaan sehingga dapat menghindari pekerjaan berlebih pada setiap anggota tim pengembang. (Granulo \& Tanovic, 2019)

\section{B. Analisis dan Perancangan}

Pada tahap perancangan, elemen gamifikasi yang akan diimplementasikan pada sistem adalah berikut (Association for Project Management, 2014):

\section{- Point}

Poin dibagi menjadi 2 yaitu coin dan diamond. Coin didapatkan saat user telah menyelesaikan semua soal di tingkat kesulitan tertentu. Setiap tingkat kesulitan memiliki poin tersendiri. Coin akan bertambah jika user telah benar menjawab pertanyaan. Sedangkan diamond bisa diperoleh saat user benar saat menjawab pertanyaan quest.

\section{- Reward}

Reward dapat dibeli dengan menggunakan poin yang telah dikumpulkan user. Bentuk reward adalah item. Item yang diimplementasikan ke sistem ini adalah kunci jawaban. Jika user menggunakan kunci jawaban maka akan muncul jawaban dari soal tersebut.

\section{- Badge}

Badge melambangkan kemampuan dan kinerja user yang dilampirkan secara permanen ke profil user, berfungsi sebagai catatan prestasi yang terlihat. User mendapatkan badges dalam kondisi tertentu.

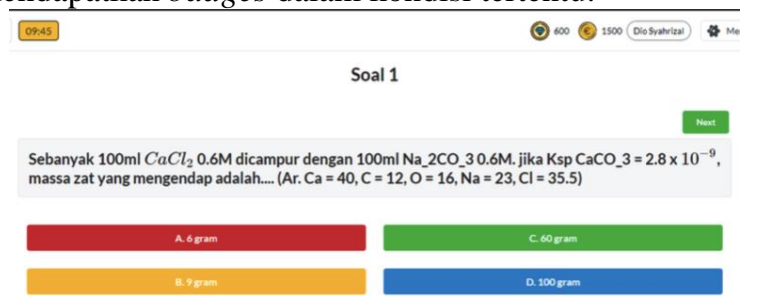

Gambar 1. Tampilan halaman soal

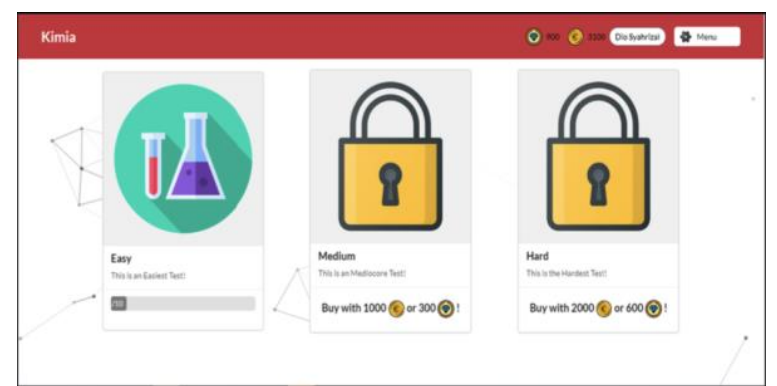

Gambar 2. Tampilan halaman dashboard pengguna

Badge yang terdapat pada sistem ini antara lain First Badges yang didapatkan saat user pertama kali menyelesaikan soal easy. Physician Badges yang didapatkan saat user sudah menyelesaikan soal-soal mata pelajaran fisika di semua tingkat kesulitan. Chemist's Badges didapatkan saat user sudah menyelesaikan soal-soal mata pelajaran kimia di semua tingkat kesulitan. Item Collector Badges didapatkan saat user membeli kunci jawaban lebih dari 3 kali. Learning to walk adalah badge yang didapatkan saat user menyelesaikan 3 soal. Pick up the Pace adalah badge yang didapatkan saat user menyelesaikan 7 soal. Owning adalah badge yang didapatkan saat user menyelesaikan 15 soal. Bone Collector adalah badge yang didapatkan saat user menyelesaikan 3 quest. Driller adalah badge yang didapatkan saat user menyelesaikan 5 quest. Archeologist adalah badge yang didapatkan saat user menyelesaikan 8 quest.

\section{- Leaderboard}

Leaderboard menampilkan peringkat tiap tingkat kesulitan dari mata pelajaran dan peringkat keseluruhan (global). Bentuk dari leaderboard adalah tabel. Dalam tampilan leaderboard ini akan menampilkan username, jumlah badge, dan poin yang dimiliki oleh setiap user. Di dalam menu leaderboard terdapat menu yang menampilkan peringkat mata pelajaran berdasarkan tingkat kesulitan. Untuk menu penilaian peringkat pada leaderboard ini berdasarkan nilai skor yang telah dijumlahkan. Leaderboard akan direset ulang saat awal bulan dan user bisa mengerjakan soal kembali.

Selain elemen-elemen pada gamifikasi, unsur-unsur gamifikasi juga akan diterapkan pada sistem yang meliputi:

- Game Mechanic

Dalam platform ini user akan menggunakan mekanisme dari game berupa pengumpulan coin, diamond, dan item berupa kunci jawaban untuk membuka tingkat kesulitan tertentu.

\section{- Game Design}

Pada platform ini akan diterapkan design yang menyerupai sebuah game agar tampilan lebih menarik, seperti design dari leaderboard dan juga badge.

\section{- Game Thinking}

Strategi dari user untuk mengatur pengeluaran coin beserta diamond adalah salah satu penerapan dari game thinking. Jika tidak, maka user tidak akan bisa membuka tingkat kesulitan yang diinginkan saat coin atau diamond tidak mencukupi. Dan juga di tingkat kesulitan medium dan hard ada batas waktu untuk mengerjakan. 


\section{Implementasi}

Implementasi sistem e-learning LBB Primagama Malang dikembangkan pada platform website dan menggunakan framework pengembangan NodeJS. Pengguna melakukan login kemudian dapat memilih menu mata pelajaran fisika, kimia, dan quest di halaman dashboard. Pada masing-masing pilihan mata pelajaran, terdapat 3 level, yaitu easy, medium, dan hard. Level easy dapat secara otomatis terbuka dan dapat langsung digunakan, namun level medium dan hard masih dalam kondisi terkunci seperti pada Error! Reference source not found.. Kedua level tersebut dapat dibuka dengan menukarkan koin atau diamond yang dimiliki oleh pengguna.

Elemen gamifikasi diimplementasikan dengan aturan-aturan tertentu. Elemen point terdiri dari coin dan diamond. Coin dapat diperoleh dengan menjawab soal dengan benar dan tidak berkurang jika menjawab salah atau tidak menjawab soal. Diamond dapat diperoleh dengan menjawab soal pada menu quest. Tampilan halaman soal dapat dilihat pada Error! Reference source not found.

Elemen kedua adalah reward. Reward berupa item yang didapatkan dengan cara menukarkan point dengan kunci jawaban jika kesulitan untuk menjawab.

Elemen ketiga adalah badge yang dapat diraih ketika menyelesaikan kasus-kasus tertentu. Contoh pada badge learning to walk, badge tersebut didapatkan pengguna ketika menyelesaikan 3 soal dengan benar secara beruntun. Menu badge untuk melihat badge yang telah dimiliki oleh pengguna atas capaian yang telah didapatkan seperti pada Gambar 4.

Elemen keempat adalah leaderboard yang menampilkan peringkat pengguna yang telah mengerjakan soal dari semua mata pelajaran. 3 pengguna dengan poin tertinggi divisualisasikan dengan

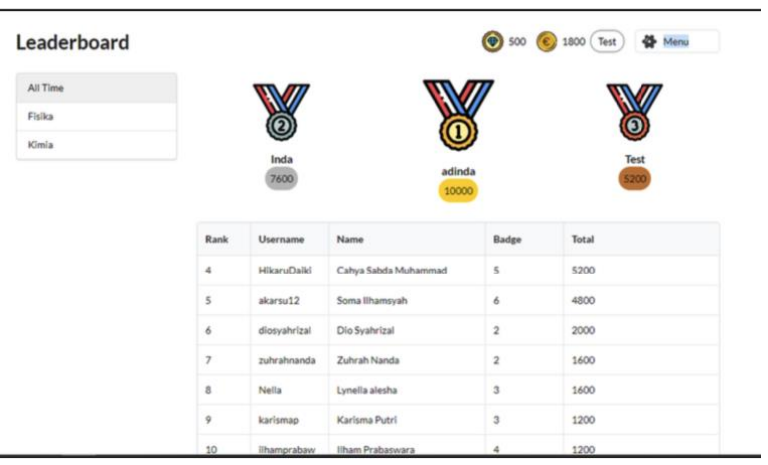

Gambar 3. Tampilan halaman leaderboard

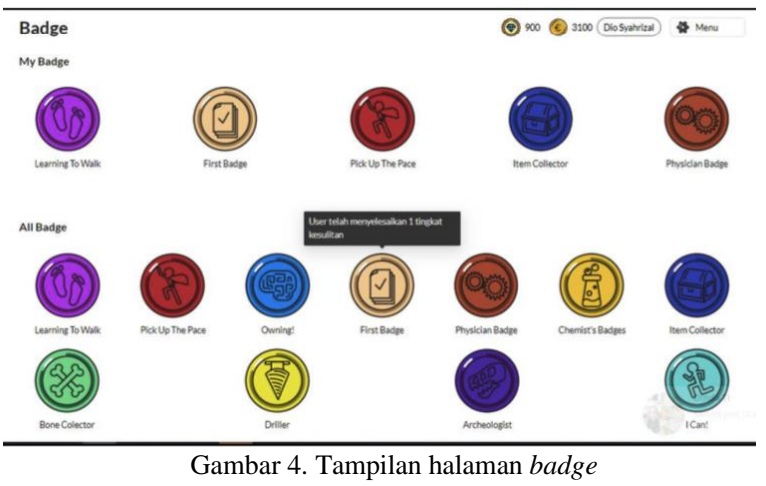

MATICS Jurnal Ilmu Komputer dan Teknologi Informasi gambar medali (emas, perak, dan perunggu). Menu leaderboard juga dapat menampilkan peringkat pengguna pada masing-masing mata pelajaran. Contoh tampilan leaderboard dapat dilihat pada Gambar 3 .

\section{Pengujian}

Pengujian sistem dilakukan dengan pengujian Blackbox untuk memastikan secara fungsional sistem telah berfungsi dengan baik. Pengujian selanjutnya adalah dengan mengujikan sistem secara langsung kepada pengguna, yaitu peserta didik di LBB Primagama Malang yang kemudian dilakukan pengisian kuesioner terkait peningkatan ketertarikan dalam belajar menggunakan sistem yang telah dibangun. Masingmasing pertanyaan pada kuesioner dihitung menggunakan skala likert dengan rincian berikut:

- Skala 1: Sangat tidak setuju.

- Skala 2: Tidak setuju.

- Skala 3: Ragu-ragu.

- Skala 4: Setuju.

- Skala 5: Sangat setuju.

Pertanyaan-pertanyaan yang terdapat pada kuesioner dapat dilihat pada Sistem pembelajaran daring yang melibatkan unsur gamifikasi ini diujikan pada peserta didik di LBB Primagama Malang. Dari hasil perhitungan kuesioner dengan skala likert didapatkan indeks penilaian seperti pada Gambar 5. Kelima pertanyaan ini mewakili variabel minat belajar yaitu terkait ketertarikan, semangat belajar, rutinitas berlatih, kenyamanan, dan membantu dalam belajar.

Pada pertanyaan pertama didapatkan indeks penilaian sebesar 90\% yang dapat diartikan peserta didik sangat setuju terhadap pernyataan ketertarikan dalam belajar mereka meningkat setelah menggunakan platform belajar yang menggunakan konsep gamifikasi. Pada pertanyaan kedua didapatkan hasil indeks penilaian sebesar $80 \%$ yang dapat diartikan peserta didik setuju bahwa platform belajar yang menggunakan konsep gamifikasi ini meningkatkan semangat belajar para peserta didik. Pertanyaan ketiga didapatkan hasil indeks penilaian $72 \%$ yang dapat diartikan perserta didik setuju jika menggunakan sistem ini, mereka akan lebih rutin berlatih dalam mengerjakan soal-soal. Pertanyaan keempat didapatkan indeks penilaian sebesar $84 \%$ yang menunjukkan peserta didik merasa sangat nyaman menggunakan sistem ini sebagai sarana

Tabel 1. Daftar pertanyaan pada kuesioner

\begin{tabular}{cl}
\hline \hline No & \multicolumn{1}{c}{ Pertanyaan } \\
\hline 1 & $\begin{array}{l}\text { Apakah dengan platform gamifikasi ini dapat } \\
\text { meningkatkan ketertarikan anda dalam belajar? }\end{array}$ \\
\hline 2 & $\begin{array}{l}\text { Apakah dengan platform gamifikasi ini dapat } \\
\text { meningkatkan semangat belajar anda? }\end{array}$ \\
\hline 3 & $\begin{array}{l}\text { Apakah setelah mengetahui platform ini, anda } \\
\text { lebih rutin berlatih mengerjakan latihan soal } \\
\text { menggunakan platform terkait? }\end{array}$ \\
\hline 4 & $\begin{array}{l}\text { Apakah anda merasa nyaman menggunaan } \\
\text { platform gamifikasi ini untuk sarana belajar? }\end{array}$ \\
\hline 5 & $\begin{array}{l}\text { Apakah fitur dalam platform gamifikasi ini } \\
\text { membantu anda dalam belajar? }\end{array}$ \\
\hline \hline
\end{tabular}

belajar. Pada pertanyaan terakhir didapatkan indeks 
penilaian sebesar $82 \%$ yang dapat diartikan bahwa peserta didik setuju sistem ini membantu mereka dalam melakukan aktivitas belajar.

Hasil nilai indeks dari 5 pertanyaan tersebut kemudian dirata-rata dan didapatkan indeks penilaian sebesar $81,60 \%$ yang dapat diartikan peserta didik setuju sistem ini meningkatkan minat belajar mereka. Hal ini tidak lepas dari penerapan konsep gamifikasi dalam sistem pembelajaran daring yang mencakup elemen gamifikasi berupa point, reward, badge, dan leaderboard, serta unsur gamifikasi yang berupa game mechanic, game design, dan game thinking. Pengguna sebagai peserta didik merasakan pengalaman yang berbeda dalam belajar karena menghadapi sistem seperti ketika mereka bermain game..

\section{HASIL DAN PEMBAHASAN}

Sistem pembelajaran daring yang melibatkan unsur gamifikasi ini diujikan pada peserta didik di LBB Primagama Malang. Dari hasil perhitungan kuesioner dengan skala likert didapatkan indeks penilaian seperti pada Gambar 5. Kelima pertanyaan ini mewakili variabel minat belajar yaitu terkait ketertarikan, semangat belajar, rutinitas berlatih, kenyamanan, dan membantu dalam belajar.

Pada pertanyaan pertama didapatkan indeks penilaian sebesar 90\% yang dapat diartikan peserta didik sangat setuju terhadap pernyataan ketertarikan

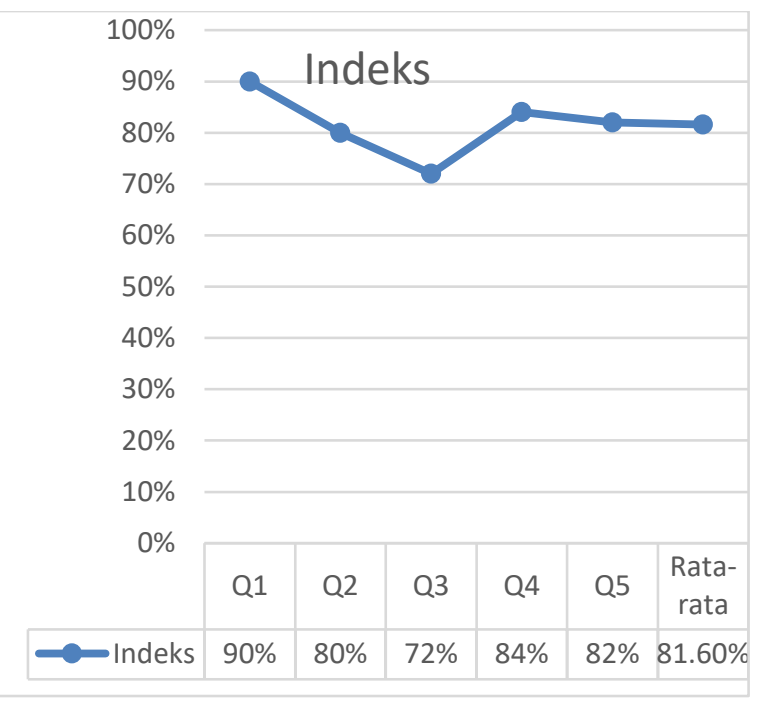

Gambar 5. Hasil penghitungan data kuesioner pengguna

dalam belajar mereka meningkat setelah menggunakan platform belajar yang menggunakan konsep gamifikasi. Pada pertanyaan kedua didapatkan hasil indeks penilaian sebesar $80 \%$ yang dapat diartikan peserta didik setuju bahwa platform belajar yang menggunakan konsep gamifikasi ini meningkatkan semangat belajar para peserta didik. Pertanyaan ketiga didapatkan hasil indeks penilaian $72 \%$ yang dapat diartikan perserta didik setuju jika menggunakan sistem ini, mereka akan lebih rutin berlatih dalam mengerjakan soal-soal. Pertanyaan keempat didapatkan indeks penilaian sebesar $84 \%$ yang menunjukkan peserta didik merasa sangat nyaman menggunakan sistem ini sebagai sarana belajar. Pada pertanyaan terakhir didapatkan indeks penilaian sebesar $82 \%$ yang dapat diartikan bahwa peserta didik setuju sistem ini membantu mereka dalam melakukan aktivitas belajar.

Hasil nilai indeks dari 5 pertanyaan tersebut kemudian dirata-rata dan didapatkan indeks penilaian sebesar $81,60 \%$ yang dapat diartikan peserta didik setuju sistem ini meningkatkan minat belajar mereka. Hal ini tidak lepas dari penerapan konsep gamifikasi dalam sistem pembelajaran daring yang mencakup elemen gamifikasi berupa point, reward, badge, dan leaderboard, serta unsur gamifikasi yang berupa game mechanic, game design, dan game thinking. Pengguna sebagai peserta didik merasakan pengalaman yang berbeda dalam belajar karena menghadapi sistem seperti ketika mereka bermain game.

\section{KESIMPULAN}

Pada penelitian ini dapat ditarik kesimpulan bahwa pembelajaran menggunakan platform pembelajaran daring meningkatkan ketertarikan pengguna dalam kegiatan belajar. Sebagaimana hasil nilai rata-rata yang didapatkan pada kuesioner sebesar $81,60 \%$. Dengan adanya penerapan konsep gamifikasi pada sistem pembelajaran daring, hal tersebut dapat membantu peserta didik untuk meningkatkan ketertarikan dalam melakukan aktivitas belajar. Peningkatan minat dan ketertarikan dalam belajar tersebut karena diterapkannya elemen gamifikasi pada sistem seperti reward yang berupa coin dan diamond, leaderboard, dan badges.

\section{REFERENSI}

Association for Project Management. (2014). Introduction to Gamification. Buckinghamshire.

Barrio, C. M., Organero, M. M., \& Soriano, J. S. (2016). Can gamification improve the benefits of student response systems in learning? An experimental study. IEEE TRANSACTIONS ON EMERGING TOPICS IN COMPUTING.

Fathoni, A. C., \& Delima, D. (2016). Gamification of Learning Kanji with "Musou Roman" Game. 2016 1st International Conference on Game, Game Art, and Gamification (ICGGAG). Jakarta.

Granulo, A., \& Tanovic. (2019). Comparison of SCRUM and KANBAN in the Learning Management System implementation process. 27th Telecommunications forum TELFOR 2019. Belgrade, Serbia.

Handani, S. W., Suyanto, M., \& Sofyan, A. F. (2016). PENERAPAN KONSEP GAMIFIKASI PADA E-LEARNING UNTUK PEMBELAJARAN ANIMASI 3 DIMENSI. Jurnal Telematika, 9, 42-53.

Heryadi, Y., Robbany, A. Z., \& Sudarma, H. (2016). User Experience Evaluation of Virtual RealityBased Cultural Gamification Using GameFlow Approach. 2016 1st International Conference 
on Game, Game Art, and Gamification (ICGGAG). Jakarta.

Kusmana, A. (2011). E-Learning dalam Pembelajaran. Lentera Pendidikan, 35-51.

Mubin, S. A., \& Poh, M. W. (2019). A Review on Gamification Design Framework: How They Incorporated for Autism Children. 2019 4th International Conference and Workshops on Recent Advances and Innovations in Engineering (ICRAIE). Kedah.

Prakasa, F., \& Emanuel, A. (2019). Review of Benefit Using Gamification Element for Countryside Tourism. 2019 International Conference of Artificial Intelligence and Information Technology (ICAIIT). Yogyakarta.

Rienzo, A., \& Cubillos, C. (2019). Research of Gamification Techniques and their Application in Digital Games for Older Adults. 2019 IEEE CHILEAN Conference on Electrical,

Electronics Engineering, Information and Communication Technologies (CHILECON). Valparaiso.

Rozi, F., Rosmansyah, Y., \& Dabarsyah, B. (2019). A Systematic Literature Review on Adaptive Gamification: Components, Methods, and Frameworks. 2019 International Conference on Electrical Engineering and Informatics (ICEEI). Bandung.

Sari, P. (n.d.). Memotivasi Belajar dengan Menggunakan E- Learning. Jurnal Ummul Qura, 20-35.

Tóth, Á., \& Tóvölgyi, S. (2016). The introduction of gamification: A review paper about the applied gamification in the smartphone applications. 2016 7th IEEE International Conference on Cognitive Infocommunications (CogInfoCom). Wroclaw.

Wu, C.-H., Chen, C.-C., Wang, S.-M., \& Hou, H.-T. (2018). The Design and Evaluation of a Gamification Teaching Activity Using Board Game and QR Code for Organic Chemical Structure and Functional Groups Learning. 2018 7th International Congress on Advanced Applied Informatics (IIAI-AAI). Yonago. 